\title{
RECONOCIMIENTO INTERNACIONAL DE LAAMPLIACIÓN DE LA PLATAFORMA SUBMARINA ARGENTINA
}

\author{
Jorge R. Mariño Fages $(h)^{l}$
}

\section{Antecedentes}

Para comprender el tema que se trata, se cree conveniente contextualizarlo en el ámbito más amplio del derecho internacional del mar, sus antecedentes y evolución.

La navegación y el aprovechamiento de las riquezas del mar por el hombre y los pueblos, con el transcurso del tiempo fue gestando por la costumbre internacional el reconocimiento de dos espacios marítimos: el mar territorial, en donde la unidad política costera ejerce dominio, y el alta mar o mar libre, donde no hay jurisdicción de ninguna unidad política y se puede navegar y pescar libremente.

En lo que se refiere al mar territorial, Grocio en De Mare Liberum (1609), afirmaba que el Estado costero tenía imperio sobre las aguas adyacentes y en esa misma tendencia, Selden en el libro Mare Clausum (1613) sostenía que el mar adyacente a las costas se hallaba en situación distinta a la alta mar, por lo que dio fundamento para que Inglaterra prohibiera en sus costas, la pesca por parte de buques holandeses. ${ }^{2}$

Así, en el período identificado como Derecho Internacional Clásico (1648/1945), se aceptaba que el Estado costero ejerciera soberanía sobre su mar territorial, por lo que conforme a ello tenía poder absoluto sobre dicho espacio, limitado solamente por el "paso inocente", consistente en el derecho de navegación sin detención (paso simple, rápido e ininterrumpido) por el mar territorial y el ingreso y salida de las aguas interiores, por parte de los buques extranjeros, sin necesidad del pedido de autorización para navegar; presumiéndose el paso como inocente mientras no fuera perjudicial para la paz, el buen orden o la seguridad del Estado ribereño.

${ }^{1}$ Profesor Titular de Derecho Internacional Público de la Facultad de Derecho y Ciencias Sociales y Políticas de la UNNE, Cátedra "A". Magister en Procesos de Integración Regional, Doctor en Derecho Público, Política y Gobierno.

${ }^{2}$ Podesta Costa, L.A. Ruda, José María, "Derecho Internacional Público", T. 1, p. 252, Tea, 1985, Buenos Aires. 
En lo que hace a alta mar, para los romanos el Mar Mediterráneo era considerado como mar de ellos, por lo que lo denominaban mare nostrum.

En los Siglos XV y XVI, durante la vigencia del Derecho Internacional Clásico, Portugal se atribuyó derechos exclusivos de navegación, exploración y conquista, en virtud de la Bula inter caetera, de Alejandro VI, que había asignado el oriente de la línea meridiana (ubicada a 100 leguas al oeste de las islas Azores y Cabo Verde) para Portugal y el occidente para España.

Contradiciendo la pretensión de Portugal sobre el océano Atlántico, que afectaba los intereses de Holanda, Estado también marítimo, Grocio en De Mare Liberum, asentaba que los mares no podían apropiarse porque no eran susceptibles de ocupación y por lo tanto, no estaban sometidos al dominio, jurisdicción, ni pesca exclusiva de ningún Estado. ${ }^{3}$

Esa era también la posición, en el Siglo XVI de Francisco de Vitoria y Fernando Vázques de Menchaca, quienes hacían alusión al derecho de todos a la navegación de los mares como norma del derecho natural corroborada por el uso común.

Recién alrededor de 1830 en adelante, quedo abandonada la idea de poder apoderarse del mar por cualquier Estado, afianzándose finalmente el reconocimiento del principio de la "libertad de los mares", por lo que su naturaleza jurídica paso a ser interpretada como una res comunis usus (cosa de uso común).

A medida que fue pasando el tiempo, se veía la necesidad de que esas costumbres sobre el uso y el aprovechamiento de los mares, se cristalizaran en normas escritas.

Así, durante la vigencia de la Sociedad de las Naciones, se llevó a cabo en el año 1930 una Conferencia en La Haya, para la Codificación del Derecho Internacional, que entre otras cosas intentó codificar el régimen jurídico del mar territorial, pero no se logró aprobar ninguna norma, por lo que resulto un gran fracaso. ${ }^{4}$

Ya en el marco de las Naciones Unidas, se vuelve a insistir con la idea de tratar de regimentar los derechos y obligaciones del mar, por lo que en esa

${ }^{3}$ Pastor Ridruejo, José A., "Curso de Derecho Internacional Público y Organizaciones internacionales", p. 403, Tecnos, 1992, Madrid y Podesta Costa, L. A. y Ruda, José María, ob. cit., p. 252.

${ }^{4}$ Conf. Diez de Velazco, Manuel, "Instituciones de Derecho Internacional Público", p. 373, Tecnos, 1997, Madrid. 
inteligencia se suscriben las Convenciones de Ginebra de 1958, por las cuales se dividió la superficie del espacio marítimo en: mar territorial; zona contigua y alta mar; incluso se reglamentó la pesca en este último espacio y en el subsuelo marino se trató sobre la plataforma submarina.

Pero los Convenios de Ginebra no tuvieron todo el éxito que se esperaba ya que muchos Estados no los ratificaron, porque rápidamente se quedaron desactualizados por distintas circunstancias económicas, políticas, tecnológicas y estratégicas. ${ }^{5}$

\section{La Convención de Jamaica}

Luego de varios años y sesiones, las Convenciones de Ginebra, fueron reemplazadas, por la Convención sobre el Derecho del Mar (CONVEMAR) que fue aprobada en Montego Bay, Jamaica, en diciembre de 1982 y que entró en vigor en 1994, al haber recibido las 60 ratificaciones necesarias para su vigencia conforme al art. 308 . Nuestro país la aprobó por Ley $\mathrm{N}^{\circ} 24543^{6}$ y la ratificación la depositó el 1/12/1995: desde su concreción, al 3/5/2016, son partes del tratado 167 Estados. $^{8}$

La ley argentina además de aprobar la Convención, formula varias declaraciones y reserva, entre ellas sobre al Acta Final de la III Conferencia de las Naciones Unidas, para que no le afecte en modo alguno la "Cuestión de las Islas Malvinas", ratificando su legítima e imprescriptible soberanía sobre dichas islas, las islas Sándwich del Sur y Georgias del Sur y los contornos marítimos correspondientes.

Este Tratado es considerado la Carta Magna del Mar9 y divide la superficie marítima en el Mar Territorial, la Zona Contigua, la Zona Económica Exclusiva y el Mar Libre o Alta Mar y en el subsuelo marino la Plataforma Submarina y los Fondos Marinos.

${ }^{5}$ Pastor Ridruejo, José A. ob.cit., pp. 355-357. https://treaties

${ }^{6}$ Ministerio de Economía y Finanzas Públicas (MECON), Centro de Documentación e Información; Información Legislativa (Infoleg), Convenciones, Ley $\mathrm{N}^{\circ} 24543$, en [http://infoleg. mecon.gov.ar/infolegInternet/anexos/25000-29999/28913/norma.htm].

${ }^{7}$ ONU. Derecho del Mar, en [www.prodiversitas.bioetica.org/doc $115 \mathrm{htm}$ ].

8 Treaty Collection, United Nations, New York, en fecha 3/5/2016, en [https://treaties. un.org/pages/ViewDetailsIII.aspx?src=TREATY\&mtdsg_no=XXI-6\&chapter $=21 \&$ Temp $=m t d$ sg3\&lang=en].

${ }^{9}$ El entonces presidente de la III Conferencia de las Naciones Unidas sobre el Derecho del Mar, T. B. Koh, expresó en la sesión final de la Conferencia, que el tratado era como una "Constitución de los Océanos"; en [www.un.org/depts/los/convention_agreements/texts/koh_english.pdf]. 
El Mar Territorial fue fijado en 12 millas marinas a contar desde la más baja marea de la costa, donde el Estado costero ejerce la soberanía, con la limitación del "paso inocente" (Parte 2, Secciones 1, 2 y 3); a ello le sigue la Zona Contigua hasta las 24 millas, en el cual el Estado costero tiene funciones de fiscalización aduanera, fiscal, sanitaria y de inmigración (Parte 2, Sección 4); luego le continúa la Zona Económica Exclusiva de 200 millas marinas, a contar desde la costa, con el derecho exclusivo de exploración, explotación, conservación y administración de los recursos naturales de la zona (Parte 5) y finalmente el remanente del espacio acuático como Alta Mar, con el reconocimiento de las libertades marítimas (navegación, sobrevuelo, pesca, explotación económica e investigación científica), pero más acotadas en razón de la preocupación por la protección del medio ambiente marino y la preservación de las especies ictícolas (Parte 7).

El subsuelo marítimo, quedó repartido por la Plataforma Submarina y los Fondos Marinos individualizado como "la Zona", consagrado como "patrimonio común de la humanidad" (Parte 11).

\section{La Plataforma Submarina}

Se entiende por Plataforma Submarina el suave declive de la superficie terrestre continental e insular que penetra en el mar hasta cierta distancia, o sea la prolongación natural del continente en el mar.

Doctrinariamente hacia 1918, el profesor León Suarez de la UBA sostenía la necesidad de que el Estado adyacente a la plataforma submarina debería ejercer en las aguas de ésta la vigilancia y la explotación exclusiva de la pesca y la caza marítima.

Normativamente, en 1944, la Argentina dicta el decreto $\mathrm{N}^{\circ} 1386$ declarando zona transitoria de reservas mineras el mar epicontinental, que es el que cubre la plataforma submarina. Al año siguiente, en 1945, la noción de la "plataforma submarina" aparece en la Declaración Truman en los siguientes términos: "que las riquezas naturales del lecho y del subsuelo de la plataforma continental en el alta mar contigua a las costas de los Estados Unidos están sometidas a su jurisdicción y control, sin perjuicio del derecho de libre navegación"; en esa misma tendencia muchos otros países fueron adoptando similar criterio entre ellos la Argentina en 1946, por Decreto $N^{\circ} 14708$. 
En la Convención de Ginebra de 1958, se define a la "plataforma submarina": como a) el lecho del mar y el subsuelo de las zonas marinas adyacentes a las costas pero situadas fuera de la zona del mar territorial hasta una profundidad de 200 metros o, más allá de este límite hasta donde las aguas suprayacentes permitan la explotación de los recursos naturales de dichas zonas; b) el lecho del mar y el subsuelo de las regiones submarinas análogas, adyacentes a las costas de islas. Es decir que adoptaba una posición de verticalidad (200 metros de profundidad).

La Convención de Jamaica mide la plataforma submarina de otra forma al aceptar un criterio de horizontalidad inicial, para poder satisfacer los intereses de los Estados con plataformas muy extendidas y los de aquellos sin plataforma o con una plataforma muy estrecha. ${ }^{10}$

Es decir que a todos los países costeros se le reconoce una extensión de 200 millas marinas en carácter de Plataforma Continental y un adicional de hasta 350 millas marinas medidas desde las líneas de base o a 100 millas desde la isóbata ${ }^{11}$ de 2.500 metros de profundidad, para aquellos Estados que tuvieran una plataforma geológica natural a condición de poder presentarla y probarla ante la Comisión de Límites de la Plataforma Continental (Parte 6).

A su vez, la Comisión de Límites de la Plataforma Continental se encuentra regulada en el Anexo 2, de la CONVEMAR, y se integra con 21 miembros expertos en geología, geofísica o hidrografía, elegidos por los Estados Partes, respetando una representación geográfica equitativa, por un período de 5 años, pudiendo ser reelegidos y cumpliendo con sus funciones a título personal. A menos que se decida otra cosa, la Comisión funciona mediante Subcomisiones de 7 miembros, ante quienes se deben hacer las presentaciones o actuaciones. Luego del procedimiento ante la Subcomisión, está emite sus recomendaciones al Plenario de la Comisión para su aprobación. Los límites establecidos en las recomendaciones y aprobadas por el Plenario son definitivos y obligatorios.

A los efectos del reconocimiento de la ampliación de la plataforma submarina de nuestro país, se creó la Comisión Nacional del Límite Exterior de la Plataforma Continental (COPLA) en el año 1997, por Ley $\mathrm{N}^{\circ} 24815$, que es presidida por el Ministerio de Relaciones Exteriores e integrada por un miembro del Servicio de Hidrografia Naval y un miembro del Ministerio de Economía

${ }^{10}$ Barboza, Julio, "Derecho Internacional Público", pp. 503-504, Zavalía, 2004, Buenos Aires.

${ }^{11}$ Se entiende por isóbata la curva para la representación cartográfica de los puntos de igual profundidad en océanos y mares, así como en lagos grandes. Diccionario de la Real Academia Española, en [www.dle.rae.es/?id=MBXp1OE]. 
y Finanzas y asistidos por un Coordinador General, a su vez para el desarrollo del trabajo científico cuenta con profesionales de distintas disciplinas como geodestas, hidrógrafos, geólogos, geofísicos, cartógrafos, oceonógrafos, expertos en información geográfica y especialistas en derecho internacional. ${ }^{12}$

La Comisión Nacional presentó las conclusiones a la Comisión de Límites en el año 2009 y en abril del año 2012 se creó la Subcomisión para la Argentina.

En su informe nuestro país incorporó alrededor de $1.782 .000 \mathrm{~km} 2$, de plataforma continental argentina más allá de las 200 millas marinas $;{ }^{13}$ y luego de 9 rondas de actuaciones, la Subcomisión aprobó las recomendaciones en diciembre de 2015 y se pasó al Plenario que las adoptó por consenso el 11 de marzo de $2016 .^{14}$

\section{Derechos y obligaciones}

Los Estados ribereños ejercen derechos de soberanía sobre la plataforma submarina a los efectos de su exploración y explotación de forma exclusiva y excluyente de sus recursos naturales.

Los recursos naturales a los que hace referencia son los recursos minerales y otros recursos no vivos del lecho del mar y del subsuelo, así como los organismos vivos pertenecientes a especies sedentarias, es decir aquellos que en el período de explotación están inmóviles en el lecho del mar o en su subsuelo (art. 77).

Ahora bien, en lo tocante a la explotación de los recursos naturales más allá de las 200 millas marinas, el Estado ribereño debe efectuar pagos o contribuciones en especie, anualmente, respecto de toda producción de un sitio minero, después de los primeros 5 años de producción. La tasa es del $1 \%$ del valor o volumen de la producción. Dicha tasa aumenta a razón de $1 \%$ cada año subsiguiente y al llegar al 7\% se mantendrá en lo sucesivo.

Pero si un Estado en desarrollo que es importador neto de un recurso mineral producido en su plataforma continental, se encuentra exento de tales pagos o contribuciones.

12 [http://www.plataformaargentina.gov.ar/es/la-comisión-nacional-del-límite-exterior-dela-plataforma-continental-copla].

${ }^{13}$ Comisión Nacional del Límite Exterior de la Plataforma Continental (COPLA), en [http:// www.plataformaargentina.gov.ar].

${ }^{14}$ Convención de las Naciones Unidas sobre el Derecho del Mar. Comisión de Límites de la Plataforma Continental. CLCS/93, 40 Periodo de Sesiones, New York, 1 de febrero a 18 de marzo, 2016, Tema 8, p. 5, en [https://documents-dds-ny.un.org/doc/UNDOC/GEN/N16/108/91/ PDF/N1610891.pdE?OpenElement]. 
Los pagos y las contribuciones se deben entregar a la Autoridad - conformada por la Asamblea, el Consejo y la Secretaría (art. 158.1) —, la cual los debe distribuir entre los Estados Partes sobre una base equitativa, teniendo en cuenta los intereses y necesidades de los Estados en desarrollo y especialmente los menos adelantados y los que no tienen litoral (por ej. Bolivia).

A tales efectos, el Consejo tiene que presentar a la Asamblea las recomendaciones que ésta debe aprobar por mayoría de 2/3 de los Estados presentes y votantes: arts. 160, f), 1) y 162,1$)$, o) y posteriormente tales pagos y cobros los tiene que fiscalizar (art. 162, p).

\section{Implicancias jurídicas, políticas y económicas}

Desde el punto de vista jurídico la adopción de las recomendaciones de la Comisión de Límites de la Plataforma Continental, si bien tiene un carácter técnico científico, conforme al párrafo 8 del art. 76, de la Convención de Jamaica, tal dictamen es definitivo y obligatorio, lo cual implica que no hay posibilidad de revisión o cuestionamiento legal.

No obstante la delimitación de la plataforma continental presentado por nuestro país, no condiciona, ni mejora nuestra posición respecto de la disputa de soberanía respecto de las Islas Malvinas, Georgias y Sandwichs del Sur.

A nuestro entender, sigue teniendo mayor importancia jurídica la Resolución $n^{\circ} 2065(\mathrm{XX})$ de 1965 de la Asamblea General de las Naciones Unidas, que reconoció la disputa territorial entre nuestro país y Gran Bretaña, referido a la cuestión Malvinas e invita a las partes a encontrar una solución pacífica al problema teniendo en cuenta la Resolución $\mathrm{N}^{\circ} 1514(\mathrm{XV})$ - también conocida como Carta Magna de la Descolonización que desarrolla el principio de la libre determinación de los pueblos-, así como los intereses de la población de las Islas Malvinas. $^{15}$

Dicha plataforma también se superpone con la parte que la Argentina considera que le corresponde de la Antártida, conjuntamente con las pretensiones de Gran Bretaña y Chile y que por el art.4 del Tratado Antártico de 1959, los reclamos de soberanía han quedado en suspenso, al congelarse las pretensiones de soberanía territorial de los Estados. ${ }^{16}$

${ }^{15}$ [Dipublico.org]. Derecho internacional, en [www.dipublico.org/5886/resolucion-2065-xxde-la-asamblea-general-de-las-naciones-unidas-cuestion-de-las-islas-malvinas-falkland-islands/].

${ }^{16}$ Conf. Pastor Ridruejo, José A. ob.cit, p. 503. 
Desde el punto de vista político es un reconocimiento de la comunidad internacional hacia el trabajo serio, coherente y consistente que independientemente de los gobiernos de turno vino desarrollando la Argentina desde 1997, al crearse COPLA en adelante. No caben dudas que este comportamiento reafirma la presencia de nuestro país en el Atlántico Sur.

Desde una perspectiva económica, genera no solamente una gran expectativa a futuro, por la gran potencialidad de los recursos que se podrán extraer del lecho como del subsuelo marino, sino que ya a nivel mundial se ha iniciado el proceso de explotación de dichos recursos, tales los hidrocarburos, como los componentes de los nódulos polimetálicos, compuestos por magnesio, cobre, zinc, cobalto, incluso, plata, oro y diamantes etc., ${ }^{17} \mathrm{y}$ también las especies vivas sedentarias como corales, ostras, mariscos, centollas, cangrejos, langostas, vieiras, langostinos, etc. ${ }^{18}$

\section{Conclusión}

En términos generales, cabe destacar, que fue la primera vez, que casi todos los Estados de la comunidad internacional de entonces participaron de la negociación y firma de un tratado, marcando con ello un hito histórico, que a decir de Barboza "fue uno de los esfuerzos de codificación más importantes de la historia" ${ }^{19}$ y que Pastor Ridruejo concluyera de que fue una de las convenciones que ha alcanzado el pleno éxito; ${ }^{20} \mathrm{y}$ si bien es cierto que hay algunas potencias que no lo han ratificado todavía, por reparos respecto de sus intereses nacionales, los cuestionamientos se van solucionando, como por ejemplo el acuerdo alcanzado en 1994. No hay que olvidar que el tratado regula una inmensa cantidad de

${ }^{17}$ Conf. Somoza, Luis y González, Francisco Javier, "Minería submarina. Se inicia la explotación de los océanos", en "Revista Enseñanzas de la Ciencias de la Tierra", AEPECT, Universitat de Girona, Gerona, Vol. 19, Número 1, 2011, pp. 115-118, [www.academia.edu/1026523/ Minería_submarina_se_inicia_la_explotación_de_los_fondos_oceánicos].

${ }^{18}$ Casa Rosada, Presidencia de la Nación, “QQué cambia con el nuevo límite exterior de la Plataforma Continental Argentina?", en [www.casarosada.gob.ar/gobierno-informa/35871-quecambia-con-el-nuevo-límite-exterior-de-la-plataforma-continental-argentina].

${ }^{19}$ Barboza, Julio, ob. cit., p. 485.

${ }^{20}$ Pastor Ridruejo, José Antonio, "Las Naciones Unidas y la codificación del derecho internacional: aspectos jurídicos y políticos", en "Las Naciones Unidas y el derecho internacional", p. 179, Ariel, 1997, Barcelona. 
cuestiones referidas a casi tres cuartas partes de la superficie del planeta Tierra; ${ }^{21}$ lo expresado en términos generales son de aplicación particular lógicamente a la cuestión de la plataforma submarina.

Para la Argentina específicamente resulta sumamente importante este tratado porque es un país con un extenso litoral marítimo, y por lo tanto el reconocimiento internacional de la Plataforma Continental nos deja la posibilidad de incorporar adicionalmente a nuestro dominio aproximadamente $1.780 .000 \mathrm{~km} 2$ de subsuelo marino, con toda la potencialidad de explotación de los recursos naturales (vivos y no vivos) que esto trae aparejado; claro está sin obviar la disputa de soberanía con Gran Bretaña por las Islas Malvinas y demás islas y el tema del continente antártico, que en algún momento deberá resolverse.

El funcionamiento del sistema convencional del mar, abre enormes expectativas que implican nuevos desafíos, pero también beneficios que indudablemente el mar ha de brindar a la humanidad en su conjunto y a nuestro país en particular, tanto en el presente como en el futuro.

${ }^{21}$ Gobierno de Aragón. Ciencias Sociales. Distribución de continentes y océanos, en: [http://e-ducativa.catedu.es/44700165/aula/archivo]. 